\title{
High-frequency initialisms: Evidence for Singaporean English stress
}

\author{
E-Ching $\mathrm{Ng}^{*}$
}

\begin{abstract}
In light of recent findings that Singlish (Colloquial Singaporean English) makes use of three densely distributed tones in its intonation, it has been suggested that this variety of English may lack stress. Here I show that initialisms such as NTUC (National Trade Unions Congress) display tonal variation which cannot be explained straightforwardly in terms of lexical access routes, but indicate recursive prosodic word structures linked to lexical frequency. This analysis is supported by frequency counts and acoustic measurements, and represents not only evidence of stress in Singlish, but multiple levels of stress.
\end{abstract}

Keywords. laboratory phonology; prosodic hierarchy; stress; intonation; world Englishes; abbreviations; compounds.

1. Introduction. Singlish (colloquial Singaporean English) is a contact variety strongly influenced by various regional languages, especially Southern Min Chinese and Malay. Although stigmatised in formal settings, it has become increasingly valued as a marker of national identity. As of the 2010 census, English was reported to be the dominant home language of the majority of children resident in Singapore (Singapore Department of Statistics 2011), and it is likely that most of them are being exposed to Singlish as well as 'standard English'.

Whereas most varieties of English intonation make use of high and low tonal targets, Singlish prosody is distinctive in that it has been transcribed with not two but three tones (Wee 2008, 2016; Ng 2008a, 2008b, 2009, 2010, 2011, 2012; Siraj 2008).

(1) Singlish low (L), mid (M) and high (H) tones
a. see
$\mathrm{H}$
e. machine
LH
b. apple
f. hibiscus
LMH
c. elephant
$\mathrm{MH}$
g. America
LMMH
d. Indonesia $\mathrm{MMMH}$
h. Kilimanjaro
$\mathrm{MMMMH}$
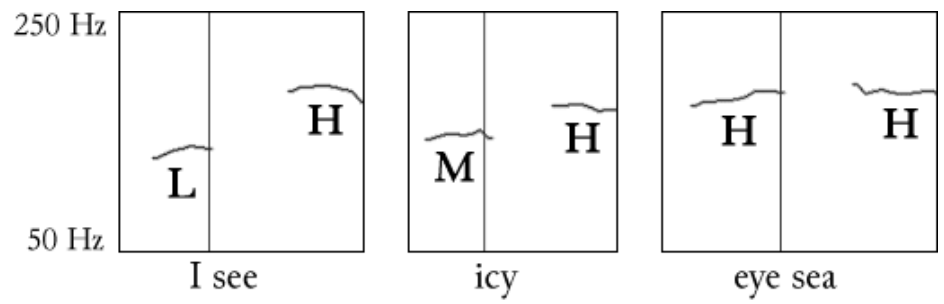

Figure 1: Singlish low, mid and high tones ( $\mathrm{Ng} 2010)$

Wee $(2008,2016)$ has suggested that since tone is so salient and densely distributed in Singlish, stress may not be present at all. He suggests that different tone patterns may be lexically indexed:

\footnotetext{
* I would like to thank Darya Kavitskaya, Matt Wolf, Stephen Anderson, Bob Frank, Jelena Krivokapić, Maria Piñango, Wee Lian Hee, Pasha Siraj, Erich Round for their advice; participants in the Prosodic Alignment workshop at Mannheim; Raffles Junior College for the use of their music facilities; Nick Huang (Zhipeng), Lim Tse Yang and Gilbert Oh for their sensitive judgments; my Singlish consultants, and all others I have omitted by request. Author: $\mathrm{Ng}$ E-Ching, University of Chicago (ng.eching@gmail.com).
} 
some words are marked as beginning with a low tone, while others are not. $\mathrm{Ng}$ and Siraj, in contrast, treat these tonal phenomena as stress-dependent intonation: mid tone is linked to (nonfinal) stressed syllables (see section 6). Both analyses are capable of accounting for the vast majority of tonal patterns in Singlish.

This study presents additional evidence that Singlish tonal patterns should be treated as stress-dependent, based on Singlish abbreviations such as MOE (Ministry of Education). These abbreviations show tonal variation which cannot be analysed in terms of phonetic reduction or lexical access. I argue that they must be analysed as the result of frequency-linked destressing.

Sections 2 and 3 describe my methods and framework respectively. Sections 4 and 5 discuss glottalisation and tone, which I use to diagnose prosodic structure. Section 6 discusses Singlish stress and how it has presented difficulties for researchers. I give my data in section 7 , and my proposed analysis in section 8 . Sections 9 and 10 support my account by showing that my predictions are borne out with respect to Google Singapore hits (as a proxy for lexical frequency) and the phonetic correlates of stress.

2. Methods and notation. The data are chiefly drawn from a series of recordings made in 20082009. Five speakers read the main script (238 test items), while three others read a supplementary script (160 test items) from which little data was drawn for this study; not all of these recordings have been transcribed yet. Almost all sentences in the script used question-andanswer pairs such as (2) below to promote natural speech. Subjects were instructed to pretend that the target word was a common brand such as Colgate.

(2) Experimenter: Can order ah?

Subject: NEVER order Differentiation from Katong lah.

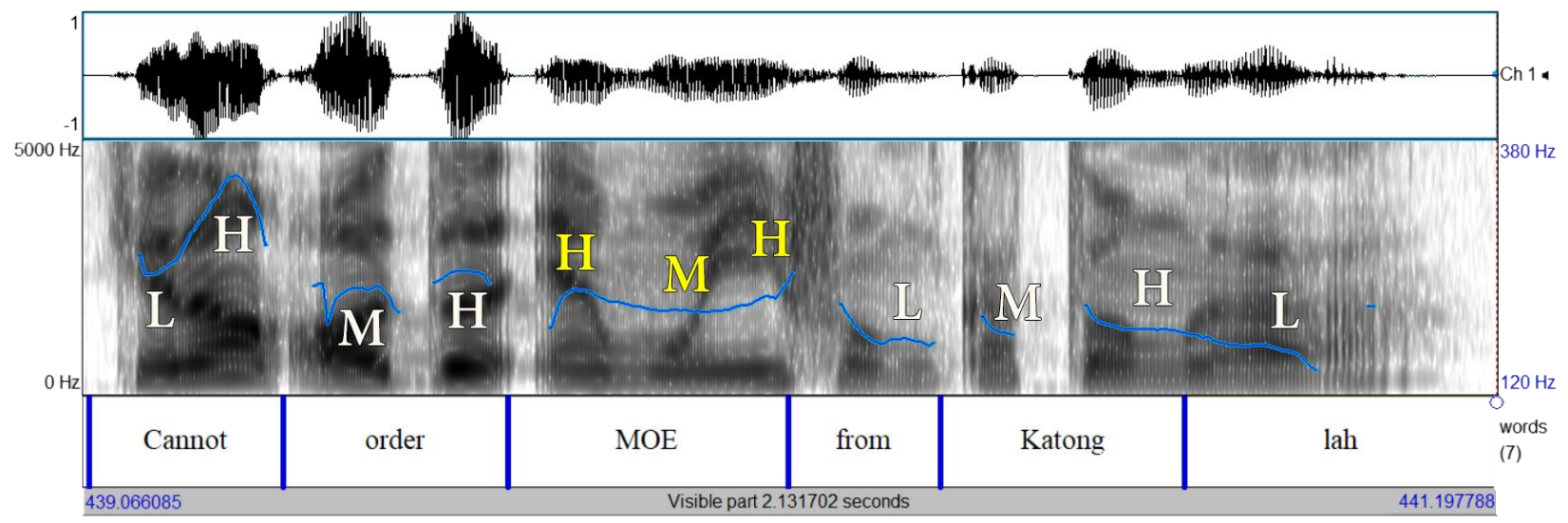

Figure 2: The target word is $M O E$.

In order to draw focus away from the target word, the initial focused word was varied between CANNOT, NEVER, BETTER and ALWAYS, and the place name was varied between Jurong, Katong and Punggol. Sentence-final ah and lah were included because they are the most common interrogative and declarative discourse particles respectively (Gupta 1992), and could therefore promote natural and authentic Singlish speech while remaining as pragmatically neutral as possible. Supplementary data comes from a combination of eavesdropping and consulting others' native-speaker intuitions on unattested forms and correct transcriptions.

Tone. This study is limited to the Singlish of ethnically Chinese Singaporeans, who represent $74.1 \%$ of Singapore residents as of the 2010 census (Singapore Department of Statistics 2011). All tones were labelled impressionistically based on my intuitions in Min 
Chinese, the subfamily of Chinese which has had the greatest influence on the formation of Singlish (Gupta 1998). As I consider myself only a semi-native speaker of either language, tone transcriptions such as HHMH and HMMH were confirmed by checking with another semi-native speaker and two native speakers of Singlish and Min Chinese.

Notation. Square parentheses indicate [morpho-[syntactic]] structure; round parentheses indicate (p)(word) (structure). Initialisms refer to lexical items like CIA; acronyms refer to forms like $C I A$ and NASA collectively. L, $\mathrm{M}$ and $\mathrm{H}$ refer to low, mid and high tone.

3. Framework. Morphology and lexical access. Psycholinguistic studies of priming (e.g. Baayen 1992; Hay 2003: ch. 4) have shown that high-frequency words tend to be lexically accessed as single whole-word units (see the dotted arrow in Figure 3 below), but low-frequency words as decomposed morphemes (see the solid arrows below).

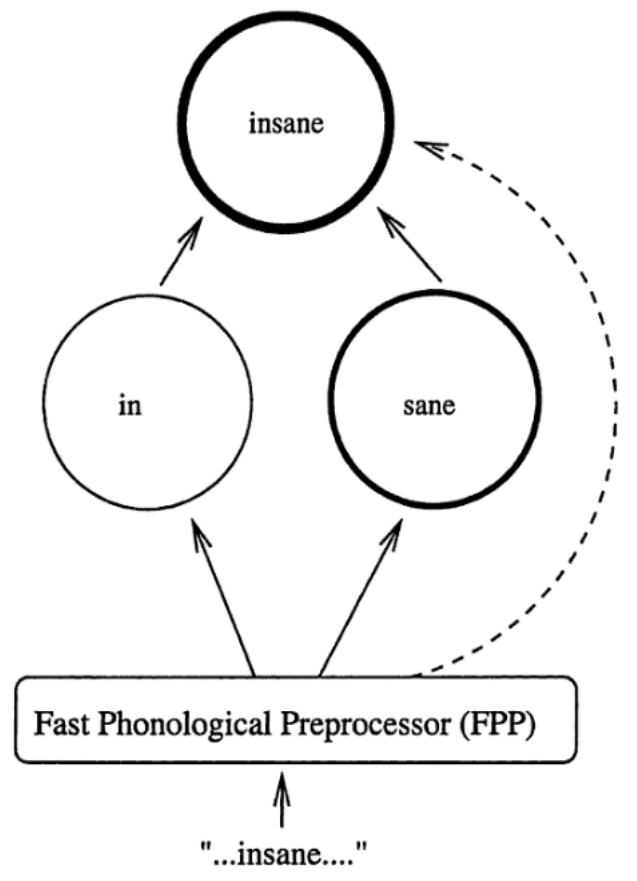

Figure 3: Whole-word vs. decomposed access (Hay 2003: 13)

There is increasing evidence that not just one, but both access routes can succeed (e.g. Baayen $\&$ Schreuder 1999; McCormick, Brysbaert \& Rastle 2009). This gives us three possible types of lexical access illustrated in (3) below.

(3) Three routes of lexical access, with lexical units accessed

\begin{tabular}{lll}
\hline a. & Whole-word-only & insane (grammatical word) \\
\hline b. & Decomposed-only access & in- (affix), sane (stem) \\
\hline c. & Mixed access & insane (grammatical word), in- (affix), sane (stem) \\
\hline
\end{tabular}

Note that since all results of access count as accessed lexical units, I will use the term grammatical word to refer to the whole-word unit, and stem to refer to any constituent which can appear as an independent grammatical word, including the whole-word unit itself.

Phonology and the prosodic hierarchy. English is generally analysed with six levels of prosodic organisation above the segment: the syllable, the foot, the prosodic word (or 
phonological word), the phonological phrase (or intermediate phrase), the intonational phrase, and the utterance phrase (Selkirk 1984; Nespor \& Vogel 1986).

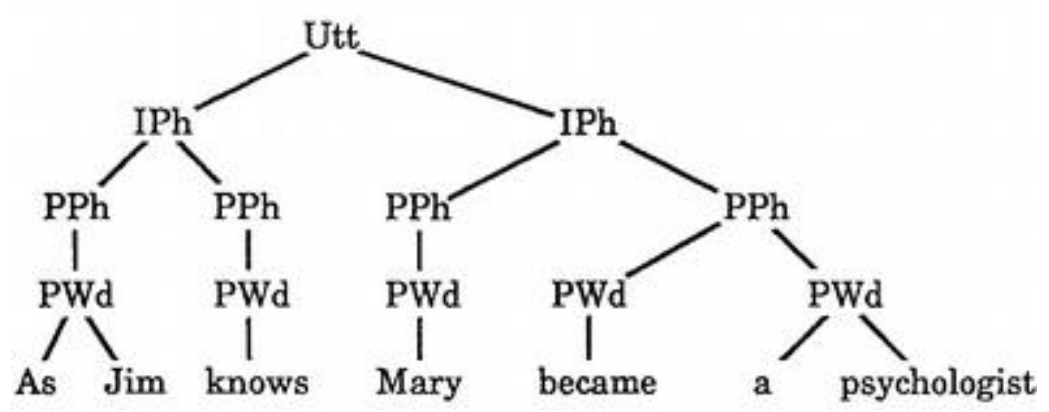

Figure 4: An illustration of the prosodic hierarchy (Ferreira 1993)

The focus of this study is the prosodic word. The pword, as I shall refer to it for brevity, is the member of the prosodic hierarchy which is of roughly the same size as a grammatical word, typically isometric with monomorphemic words. By definition, it is also the lowest-level member of the prosodic hierarchy which can be sensitive to word-internal structure (Raffelsiefen 1999: 133). Extensive cross-linguistic evidence supports the existence of recursive pwords (Inkelas 1989; McCarthy \& Prince 1993: A1; Selkirk 1995; Peperkamp 1997), which I will assume in cases of mismatched pword edges, e.g. $(\sigma(\sigma \sigma)$ implies $(\sigma(\sigma \sigma))$. This analysis also assumes that no pword can contain two identical levels of secondary stress, i.e. stress is strictly hierarchical (Liberman \& Prince 1977; Hayes 1995: 25). The restriction also applies to recursive pwords: $((\dot{\sigma}) \dot{\sigma} \sigma)$ or $((\dot{\sigma}) \dot{\sigma} \sigma)$ are possible representations, whereas $\left(\left(\sigma^{\prime}\right) \dot{\sigma} \sigma\right)$ is not.

I make the common assumption that tones can only be anchored to the edges or heads of prosodic units rather than morphosyntactic units (Beckman, Hirschberg \& Shattuck-Hufnagel 2005). This helps us to account for phenomena such as Singlish high tone, which appears only on the final syllable of monomorphemic words, but is much more variable in initialisms. I also assume that prosodic units above the syllable are created by alignment with morphosyntactic units; not necessarily isometric, but constrained such that edges align (Hall 1999: 2; McCarthy 1993).

4. Left pword edge: Glottalisation. Singlish often strikes non-speakers as 'choppy' or 'staccato' (Brown 1988), because liaison is rare even in contexts such as An apple a day (Tongue 1979: 38). Vowel-initial grammatical words are almost always marked with a glottal stop or creaky voice, which I will refer to as glottalisation. This may be observed in Figure 5 below.

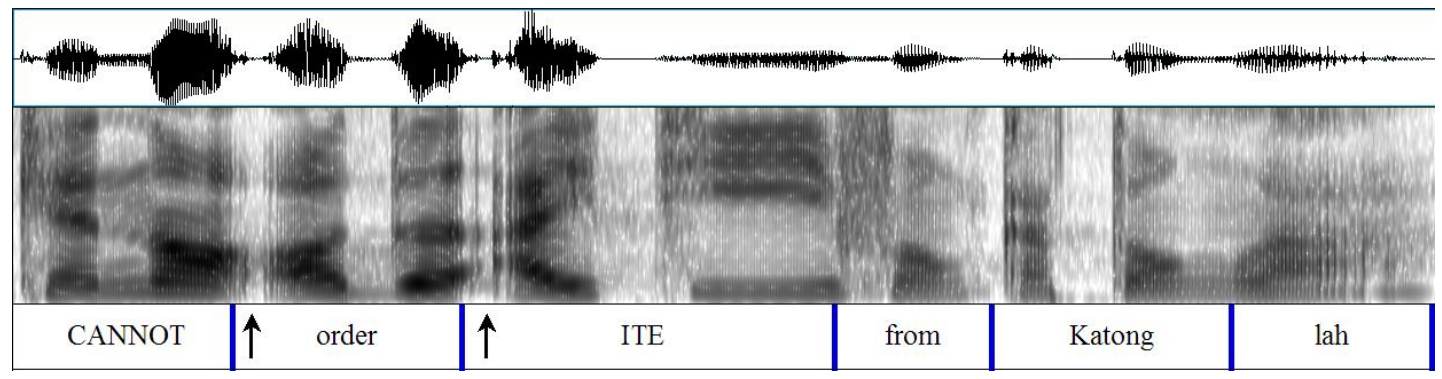

Figure 5: Glottalisation in ITE (Institute of Technical Education) 
In other varieties of English, word-initial glottalisation is a variable phonetic effect rather than a categorical pword marker (Umeda 1978; Pierrehumbert \& Talkin 1992; Redi \& ShattuckHufnagel 2001). It varies greatly by speaker and is favoured at phrase boundaries, slow speech rates, rare words and low vowels, but is disfavoured before unstressed syllables or function words. In Singlish, however, my recordings show that nearly all speakers have glottalisation not only in stressed syllables (4a), but also in unstressed syllables (4b), function words (4c) and phrase-medially (4d).

(4) Glottalisation word-initially
a. no 'apple [no '?æpəu]
c. I 'see
[?aI 'si]
b. a 'nnoy 'me [?ə'noI 'mi]
d. 'go a'way ['go ?ə'weI]

Glottalisation is not only practically categorical word-initially, but forbidden word-medially. Onsets are created by glide insertion if a high vowel is present. In cases of hiatus between two low vowels, as in the name of Singaporean poet Alfian bin Sa'at (5c), most Chinese Singaporeans attempt no repair at all, even though Malay speakers have a glottal stop.

(5) Glide insertion word-medially
a. iron [arjon], *[ai?ən]
b. wire [warjo], *[warPe]
c. Sa'at [saØat], rarely [sa?at]

Similar glottalisation facts apply in Indonesian (Pater 2001), Bulgarian (Rubach 2000), Northern Arapo and Gufang Ifugao (Smith 2002: 127ff), Guaraní, Hausa, Squamish, Wolof and numerous other languages (Flack 2007: 56ff).

Recalling the definition of the pword stated in section 3, a monomorphemic word is typically contained by a pword. As such we can use glottalisation as a diagnostic of pword left edges.

\section{(6) Diagnostic: Pword left edge}

Any site where glottalisation is typically possible signals a pword left edge.

This indicator will be important for showing that Singlish initialisms have recursive pword structures.

5. Tone: An indicator of pword right edges and stress. This study tests Ng's (2009) analysis, which reconciles various earlier proposals (Wee 2008; Ng 2008a, Siraj 2008). This analysis treats Singlish tone assignment as dependent on stress and pword edges, as illustrated with the morphologically simple words and resulting generalisations given in (7) and (8) below. (Note that these stress transcriptions are not among those which trained transcribers disagree on.)

(7) Tone in simplex words
a. 'see
'H
e. ma'chine
L'H
b. 'apple
'MH
f. hi'biscus
L'MH
c. 'elephant 'MMH
g. A'merica L'MMH
d. 'Indo, nesia 'MM, MH
h. 'Kiliman, jaro 'MMM, MH 
(8) Tone assignment generalisations

a. High tone is assigned to the final syllable of the pword.

b. Low tone is assigned to initial unstressed syllables.

c. Mid tone is assigned to all remaining syllables, starting with the first stress. ${ }^{1}$

Based on these generalisations, we can make certain inferences about pword right edges and stress. These are illustrated below in (9) and (10) below with the sentence So I can still see Peter tomorrow ('H) ( $\left.\mathrm{L} \mathrm{L}\left({ }^{\prime} \mathrm{H}\right)\right)\left({ }^{\prime} \mathrm{H}\right)\left({ }^{\prime} \mathrm{MH}\right)(\mathrm{L}$ 'MH).

(9) Diagnostic: Pword right edge

High tone indicates the final syllable of a pword, e.g. $\mathbf{H})$ L L H) H) MH) LMH).

Conversely, lack of high tone indicates a non-pword-final syllable.

(10) Diagnostic: Stress

a. Low tone indicates pword-initial unstressed syllables, e.g. 'H (L L 'H 'H 'MH (L ' MH.

b. Mid tone after any other tone indicates stress, e.g. 'H L L 'H 'H 'MH L'MH. But note that stressed final syllables will not be detected by this diagnostic.

c. High tone not preceded by mid tone indicates stress, e.g. 'H L L 'H 'H 'MH L'MH.

These indicators will help us to establish that tonal variation in Singlish initialisms is due to pword merger as a result of destressing.

6. Stress. Singlish has been said to give the acoustic impression of a tone language (Killingley 1972: 547-8), perhaps because many of the phonetic and phonological effects usually associated with English stress are weak or lacking. Singlish is strongly syllable-timed; unstressed syllables often fail to undergo vowel reduction, and schwa is found in stressed contexts (Tongue 1974: 32; Tay 1982; Brown 1988; Low 1998; Low \& Grabe 1999; Low, Grabe \& Nolan 2000; Deterding 2001, 2005, 2007: 31ff). High pitch has been identified as an especially unreliable perceptual cue for Singlish prominence (Tay 1982; Tan 2006).

Phonologically speaking, many stress-related phenomena are lacking in Singlish; for instance, there is no evidence for stress shift of any kind. Part-of-speech distinctions which rely on stress are rare (Bao 1998: 170):

(11) Lack of part-of-speech distinctions in stress

BrEng in'crease (v.) 'increase (n.) pro'ject (v.) 'project (n.)

Singlish in'crease (v.) in'crease (n.) pro'ject (v.) pro'ject (n.)

Affix-driven stress shift is blocked in favour of strong paradigm uniformity (Bao 1998: 171).

(12) Paradigm uniformity rather than affix-driven stress shift

BrEng, eco'nomic, techno'logical, aca'demic, psycho'logical

Singlish e'conomic tech'nological a'cademic psy'chological

My recordings have also failed to find clash-driven phrasal stress shift, e.g. thir 'teen 'men > 'thirteen 'men (Liberman \& Prince 1977). In a young contact variety of English it is not surprising to find invariance across syntactic contexts, but since clash and lapse processes are

\footnotetext{
${ }^{1}$ It is also possible for unstressed syllables to remain unspecified for tone ( $\left.\mathrm{Ng} 2009\right)$, but as this phenomenon is not accessible to native speaker intuitions and does not affect our diagnostics for prosodic structure, it can be omitted from this analysis without loss of generalisation.
} 
key to the hierarchical nature of stress (Hayes 1995: 25), their absence raises the question of whether Singlish prosody is best described in terms of stress.

However, at least one study finds that intensity is a significant phonetic cue for Singlish stress even when tone is not controlled for (Tan 2002). I have conducted my own mini-analysis of 41 adjacent syllable pairs among three speakers, controlling for tone, syllable type and nonword-finality, and under these conditions both duration and intensity turn out to be significant correlates of stress ( $\mathrm{p}<0.005, \mathrm{Ng} 2011)$.

This may explain why trained linguists admit that some productions are difficult or impossible to code for stress (Bao 2006: fn.3; Deterding 2007: 33), but nonetheless show a high degree of agreement in transcriptions (Tongue 1979: 34ff; Tay 1982; Bao 1998; Deterding 2007: 32). For instance, one common observation is that stress appears further rightwards than in British English (Wells 2000):

(13) Rightward stress shift in simplex words

\begin{tabular}{lllll}
\multicolumn{1}{c}{ BrEng } & Singlish & & BrEng & Singlish \\
a. 'colleague & co'lleague & b. 'differ & di'ffer \\
c. 'vehicle & ve'hicle & d. 'character & cha'racter
\end{tabular}

As we would hope, these previous stress transcriptions correctly predict variation in surface tones (Siraj 2008; Ng 2009), allowing for interference from British and American English mass media, prescriptivism and hypercorrection.

The differences between trained linguists' stress transcriptions are limited to fairly subtle distinctions, which are unfortunately crucial for this study. Most of these discrepancies cannot be distinguished by surface tone patterns, suggesting that linguists were subconsciously using tone as a cue for stress even before it was identified and analysed as stress-dependent.

(14) Secondary stress vs. lack of stress: $\mathrm{MMMH}$

Bao (2006)

Frequent clash within stems, e.g. , mo, no 'poly.

Tongue (1979: 33) No clash transcribed, e.g. socio 'logy (presumably , so.cio'lo.gy).

\section{Primary vs. secondary stress: $M H M H$}

Tongue (1979: 37)

Compounds are right-headed, ${ }^{2}$ e.g. , table 'tennis.

Uri Tadmor (p.c. July 2008) Compounds are double-headed, e.g. 'pocket 'money.

In (14), it is possible that secondary stress has been transcribed on unstressed syllables, because syllable-timing is likely to add perceived prominence where none is expected. But in (15) it is difficult to say how phonetic implementation would bias the perception of compound stress, since final lengthening might suggest right-headedness, syllable timing double-headedness, and tonal downstep ${ }^{3}$ left-headedness. Nor is it clear that we can resolve these questions by appealing to native speaker judgments: while untrained speakers can often distinguish between 'correct' and 'incorrect' pronunciations (Bao 2006), they find it extremely difficult to transcribe or produce stress distinctions, in either British English or their own speech (Tay 1982).

In contrast with the difficulty of transcribing stress, trained Chinese Singlish speakers find surface tones salient and relatively easy to classify: one of my informants was transcribing it

\footnotetext{
${ }^{2}$ In this paper, compound left- or right-headedness refers to prosodic prominence, not morpho-syntactic structure.

${ }^{3}$ Tonal downstep has not been formally described in Singlish, but Pasha Siraj (p.c. 17 November 2008) and Jeff Good (p.c. 8 Jan 2010) confirm my impression that it occurs in Singlish.
} 
even before he learnt of my project. I propose that our discussion of stress should set aside conflicting impressionistic judgments of stress, relying on more reliable transcriptions of surface tone and acoustic measures of duration and intensity instead. The main limitation of this approach is that tone assignment does not distinguish between primary and secondary stress. However, we will see that it is possible to overcome this difficulty by using tonal variation to infer patterns of destressing.

7. Data. English acronyms have been described as falling into two classes. Initialisms, like $C I A$, are pronounced as distinct letters of the alphabet, and behave syntactically like compounds, whereas other acronyms, like $N A S A$, are pronounced like proper names, and behave syntactically like them (Harley 2004).

In Singlish, initialisms are by far the more common, and they display considerable variation, as illustrated below. ${ }^{4}$ Note that pword boundaries have been indicated based on the indicators discussed above, glottalisation (pword left edge) and tone (pword right edge).

(16) 2-letter initialisms: Integrated Resort, Identity Card

\begin{tabular}{llll}
\hline & & Least merger & Most merger \\
\hline a. & $I R$ & $((\mathrm{H}) \mathrm{H})$ & \\
b. & $I C$ & $((\mathrm{H}) \mathrm{H})$ & $(\mathrm{MH})$ \\
\hline
\end{tabular}

(17) 3-letter initialisms: National Day Parade, Ministry of Education, Mass Rapid Transit

\begin{tabular}{lllll}
\hline \multicolumn{3}{c}{ Least merger } & Most merger \\
\hline a. & $N D P$ & $(((\mathrm{H}) \mathrm{H}) \mathrm{H})$ & & \\
b. $M O E$ & $(((\mathrm{H}) \mathrm{H}) \mathrm{H})$ & $((\mathrm{H}) \mathrm{MH})$ & \\
c. & $M R T$ & $(((\mathrm{H}) \mathrm{H}) \mathrm{H})$ & $((\mathrm{H}) \mathrm{MH})$ & $(\mathrm{MMH})$ \\
\hline
\end{tabular}

(18)

4-letter initialisms:

Society for the Prevention of Cruelty to Animals, Anglo-Chinese Junior College, National Registration Identity Card, National Trade Unions Congress (supermarket)

\begin{tabular}{llllll}
\hline \multicolumn{5}{c}{ Least merger } & Most merger \\
\hline a. & SPCA & $((((\mathrm{H}) \mathrm{H}) \mathrm{H}) \mathrm{H})$ & & \\
b. & ACJC & $((((\mathrm{H}) \mathrm{H}) \mathrm{H}) \mathrm{H})$ & $(((\mathrm{H}) \mathrm{H}) \mathrm{MH})$ & & \\
c. & NRIC & $((((\mathrm{H}) \mathrm{H}) \mathrm{H}) \mathrm{H})$ & $(((\mathrm{H}) \mathrm{H}) \mathrm{MH})$ & $((\mathrm{H}) \mathrm{MMH})$ & \\
d. & NTUC & $((((\mathrm{H}) \mathrm{H}) \mathrm{H}) \mathrm{H})$ & $(((\mathrm{H}) \mathrm{H}) \mathrm{MH})$ & $((\mathrm{H}) \mathrm{MMH})$ & $(\mathrm{MMMH})$ \\
\hline
\end{tabular}

Certain generalisations may be drawn from this data. Firstly, nested pwords are possible, with up to 4 levels of recursion. Secondly, there is no variation in pword left edges (as indicated by glottalisation), ${ }^{5}$ only in pword right edges (as indicated by tone). Thirdly, pwords 'merge' in a consistent direction. For $N T U C$, we find $((((\mathrm{H}) \mathrm{H}) \mathrm{H}) \mathrm{H}),(((\mathrm{H}) \mathrm{H}) \mathrm{MH}),((\mathrm{H}) \mathrm{MMH})$ and $(\mathrm{MMMH})$, such that the last two, three or four letters merge into a single pword. We do not find the first two or three letters merging into a single pword, i.e. $*(((\mathrm{MH}) \mathrm{H}) \mathrm{H}), *((\mathrm{MMH}) \mathrm{H})$, or the middle two

\footnotetext{
${ }^{4} \mathrm{HMH}$ and HMMH were far more common than MMH, MMMH and HHMH, but all have been observed in at least one speaker and one initialism.

${ }^{5}$ In my recordings, one consultant was an exception to this rule: glottalisation occurred in every syllable of initialisms, though his surface tones were consistent with the pword structure given here. Other consultants felt that this sounded slightly unnatural except in extremely careful speech.
} 
letters, i.e. *(((H)MH)H). Fourthly, we do not find low tones, even though LH is a fairly common tonal pattern in Singlish, e.g. machine, around, forget.

Rejected analysis: Lexical access routes can explain some of this variation, but not all. A possible account would rely on (i) the assumption that prosodic boundaries tend to align with the boundaries of lexical units, and (ii) the fact that initialisms are morphologically complex words, which may be accessed by different routes.

Phonology only 'sees' the units returned by lexical access, so multiple access routes can be used to explain how morphologically complex words can have multiple realisations. For example, in the case of $N T U C$, variation between $(\mathrm{MMMH})$ and $(((\mathrm{H}) \mathrm{H}) \mathrm{H}) \mathrm{H})$ can be analysed as whole-word-only access versus decomposed/mixed access: if individual letters are lexically accessed, then prosodic units can be aligned to them, resulting in recursive pword structure rather than a simple 'wrapper'. In this way, we would be able to explain the first and last columns of the three tables above, i.e. the difference between $((\mathrm{H}) \mathrm{H}),(((\mathrm{H}) \mathrm{H}) \mathrm{H}),((((\mathrm{H}) \mathrm{H}) \mathrm{H}) \mathrm{H})$ versus $(\mathrm{MH}),(\mathrm{MMH}),(\mathrm{MMMH})$.

However, the in-between columns would still remain unaccounted for. For example, NTUC can also be realised as $(((\mathrm{H}) \mathrm{H}) \mathrm{MH})$ and $((\mathrm{H}) \mathrm{MMH})$, and this would only make sense if $U C$ and $T U C$ were meaningful sub-units. To take another example, we should often hear $A C J C$ realised as $((\mathrm{MH}) \mathrm{MH})$, since $A C$ and $J C$ are also common initialisms in their own right, with the same meaning as in $A C J C$. And we would not predict the lack of * $(((\mathrm{MH}) \mathrm{H}) \mathrm{H}), *((\mathrm{MMH}) \mathrm{H})$ or $*(((\mathrm{H}) \mathrm{MH}) \mathrm{H})$. An analysis based on lexical access fails to explain these facts.

8. Proposed analysis: Destressing. I propose that we find variation in Singlish initialisms because they are left-headed compounds that undergo different degrees of destressing, resulting in different degrees of pword merger.

Destressing is governed by a cross-linguistic constraint which can be summed up as follows: "if the two stresses are unequal in strength, it is always the weaker stress that is removed" (Hayes 1995: 37). This constraint has been formalised in metrical grid theory as follows:

(19) Continuous Column Constraint (Hayes 1995: 34)

A grid containing a column with a mark on layer $n+1$ and no mark on layer $n$ is illformed. Phonological rules are blocked when they would create such a configuration. (Do not create gaps in a grid column.)

(20) Destressing in clash (Hayes 1995: 37)

a. $\times \rightarrow \emptyset /$ $\times$

b. $\times \rightarrow \varnothing / \times$

(Remove grid marks on the level where clash occurs.)

These principles predict different outcomes for left- and right-headed compound stress after destressing.

(21) Destressing a left-headed compound
a. $\times$
$\times \times \times$
$x$
$x$
$\times \times \times \rightarrow$
$\times \times \times$
$\times \times \times$
$\times \times \times$
a. 'butter, fly

b. 'butterfly

c. * butter, fly 
(22) Destressing a right-headed compound

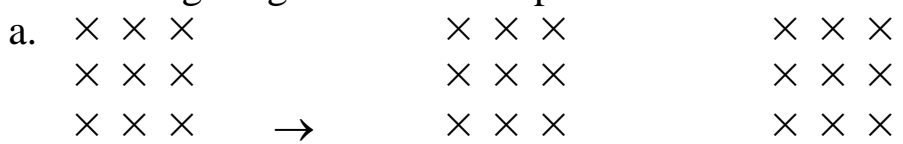

a. , butter'fly $\quad$ b. butter'fly $\quad$ c. *, butter, fly

Based on the patterns of variation observed in Singlish initialisms, we can infer that they are leftheaded. Recall that two-letter initialisms display variation between $((\mathrm{H}) \mathrm{H})$ and $(\mathrm{MH})$, whereas we do not see variation between $((\mathrm{H}) \mathrm{H})$ and $(\mathrm{LH})$. If we apply the tone diagnostics from section 5 , this means that initialisms are sometimes (' $\sigma \sigma)$, but never $\left(\sigma^{\prime} \sigma\right)$. Analysed in terms of destressing, the observed variation corresponds to left-headed $((' \sigma), \sigma)$ and (' $\sigma \sigma)$, rather than right-headed $\left((, \sigma)^{\prime} \sigma\right)$ and $\left(\sigma^{\prime} \sigma\right)$.

Left-headedness also makes the correct predictions for longer initialisms:

(23) Destressing of four-letter initialisms

\begin{tabular}{llll}
\hline & & Left-headed & Right-headed \\
\hline With no destressing & a. & $\left.\left(\left(\left({ }^{\prime} \mathrm{H}\right), \mathrm{H}\right), \mathrm{H}\right), \mathrm{H}\right)$ & $\left((((, \mathrm{H}), \mathrm{H}), \mathrm{H})^{\prime} \mathrm{H}\right)$ \\
Last letter destressed & b. & $(((\mathrm{H}), \mathrm{H}), \mathrm{MH})$ & $\left.*((\mathrm{~L}, \mathrm{H}), \mathrm{H})^{\prime} \mathrm{H}\right)$ \\
Last two letters destressed & c. & $((\mathrm{H}), \mathrm{MMH})$ & $*\left((\mathrm{LL}, \mathrm{H})^{\prime} \mathrm{H}\right)$ \\
Last three letters destressed & d. & $\left({ }^{\prime} \mathrm{MMMH}\right)$ & $\left.*(\mathrm{LLL})^{\prime} \mathrm{H}\right)$ \\
\hline
\end{tabular}

The table above also implies that the leftmost stress is strongest, since it is the last to be lost, and that the second stress is the next strongest, and so forth. Four levels of stress are implied; this may seem excessive, but it is no more than Hayes (1995: 17) has argued for in English.

9. Prediction 1: Frequency and pword merger. If it is indeed the case that Singlish initialisms display variation because they undergo different degrees of destressing, then we would predict that the observed tonal variation should be associated with factors which are known to be linked to articulatory reduction. Paramount among these is lexical frequency.

We know that high-frequency sequences such as I am going to are subject to entrenchment and reduction: their morphosyntactic forms and articulatory plans are stored, automated and processed quickly (e.g. Bybee 2006). High lexical frequency is linked to faster speech rates and shorter duration of lexical items, both of which are phonetic effects that would be conducive to destressing (Aylett \& Turk 2004; Pluymaekers, Ernestus \& Baayen 2005; Fosler \& LussieraMorgan 1999; Gahl 2008; Bell, Brenier, Gregory, Grand \& Jurafsky 2009). High-frequency Dutch words are known to display reduced spectral tilt and duration, both of which are acoustic correlates of stress (van Son \& Pols 2003). Similarly, low-frequency Russian compounds can contain secondary stress (Gouskova \& Roon, to appear).

Some segmental reduction effects also appear to be linked to frequency, such as English $t / d$ deletion, such as Taiwanese syllable coalescence (Myers \& Li 2009), Tagalog tapping $(d>r)$ and nasal substitution (e.g. $m p>m$ ) (Zuraw 2007). Interestingly, it does not appear to be a powerful predictive factor in English $\mathrm{t}$ /d-deletion, except for a few super-frequent forms such as and (Walker 2008; Guy, Hay \& Walker 2008). It may be that lexical frequency has a stronger or more direct effect on prosody than on segmental phonology.

The best frequency estimates rely on large spoken corpora, but these are not available for Singlish. The best free substitute was to count Google hits. I used Google Singapore (20 March 2010), restricting my search to Singaporean websites by appending site: . sg to the search terms. Of course, this method has its limitations. Firstly, written usage tends to be more formal 
than most speakers' lexicons; this probably explains why NRIC (National Registration Identity Card) had many more hits than IC (identity card) although any speaker can tell you that NRIC is far less common and is restricted to formal usage when disambiguation is desirable. Secondly, measuring frequency by Google hits naturally results in boosted counts for organizations with a strong Internet presence, such as NUS (the National University of Singapore). Thirdly, homophones could not be disambiguated. Two-letter initialisms proved especially noisy ${ }^{6}(\mathrm{p}=$ 0.851 for fitted-line regression of hits and duration) and were excluded from frequency analyses.

To check the hypothesis that lexical frequency predicts permitted degrees of destressing, I grouped initialisms into three ranked classes: (1) complete merger possible, (2) partial merger possible, (3) no merger possible. The initialisms were limited to the ones tested in my recordings, but class membership also took into account the forms I encountered in eavesdropping and elicitations; reclassification affected only $A C J C$ and $M R T$. Note that $L M N O$ and $L M N$ have no significance in Singlish beyond their adjacency in the alphabet.

(24) Classes of possible surface tones

\begin{tabular}{|c|c|c|}
\hline Class 1 & $\begin{array}{l}\text { Complete merger: } \\
\text { ('MMH), ('MMMH) }\end{array}$ & $M R T, N T U C$ \\
\hline Class 2 & $\begin{array}{l}\text { Partial merger: }((\mathrm{H}), \mathrm{MH}), \\
(((\mathrm{H}), \mathrm{H}), \mathrm{MH}),((\mathrm{H}), \mathrm{MMH})\end{array}$ & $\begin{array}{l}A C J C, N Y P, C C A, N R I C, S M U, L R T, \\
U O B, S I A, M O E, N T U, N U S\end{array}$ \\
\hline Class 3 & $\begin{array}{l}\text { No merger: } \\
\left(\left(\left({ }^{\prime} \mathrm{H}\right), \mathrm{H}\right), \mathrm{H}\right),((((' \mathrm{H}), \mathrm{H}), \mathrm{H}), \mathrm{H})\end{array}$ & $\begin{array}{l}L M N O, L M N, S D U, R G S, N D P, I T E \text {, } \\
C B D, G S T\end{array}$ \\
\hline
\end{tabular}

Spearman's rank order correlation between Google hits and class membership (24) found a correlation of 0.560 ( $\mathrm{p}<0.01$ ). This confirms that lexical frequency, which we can treat as a proxy for access speed, is a strong predictor of initialism destressing.

10. Prediction 2: Phonetic correlates of stress. So far we have been examining Singlish stress indirectly, through the lens of tone. This raises the question of whether Singlish stress might be more accurately analysed as an abstract underlying accent whose only phonetic manifestation is in tone. Certainly we have seen that it is less phonetically and phonologically salient than 'standard' English stress in some ways. To distinguish between stress and abstract accent, it is useful to examine the phonetic correlates of stress, such as duration and intensity. (Pitch was not considered here because of the confound of tone.)

If highly frequent words are indeed more destressed, we should expect not only pword merger (and the concomitant tonal patterns) but also shorter duration. A regression on log frequency and average syllable duration confirmed this $\left(\mathrm{R}^{2}=35.2 \%, \mathrm{p}<0.005\right)$. The fitted-line plot appears in Figure 6 below. As predicted by the hypothesis, more frequent initialisms have shorter syllable durations. This provides additional confirmation that lexical frequency is a predictor of initialism destressing.

\footnotetext{
${ }^{6}$ It is possible that less widespread initialisms like $T P$ had artificially boosted counts because they can have different uses in different contexts (Temasek Polytechnic, Toa Payoh, Traffic Police), whereas universally known initialisms like $I C$ were less likely to be polysemous.
} 


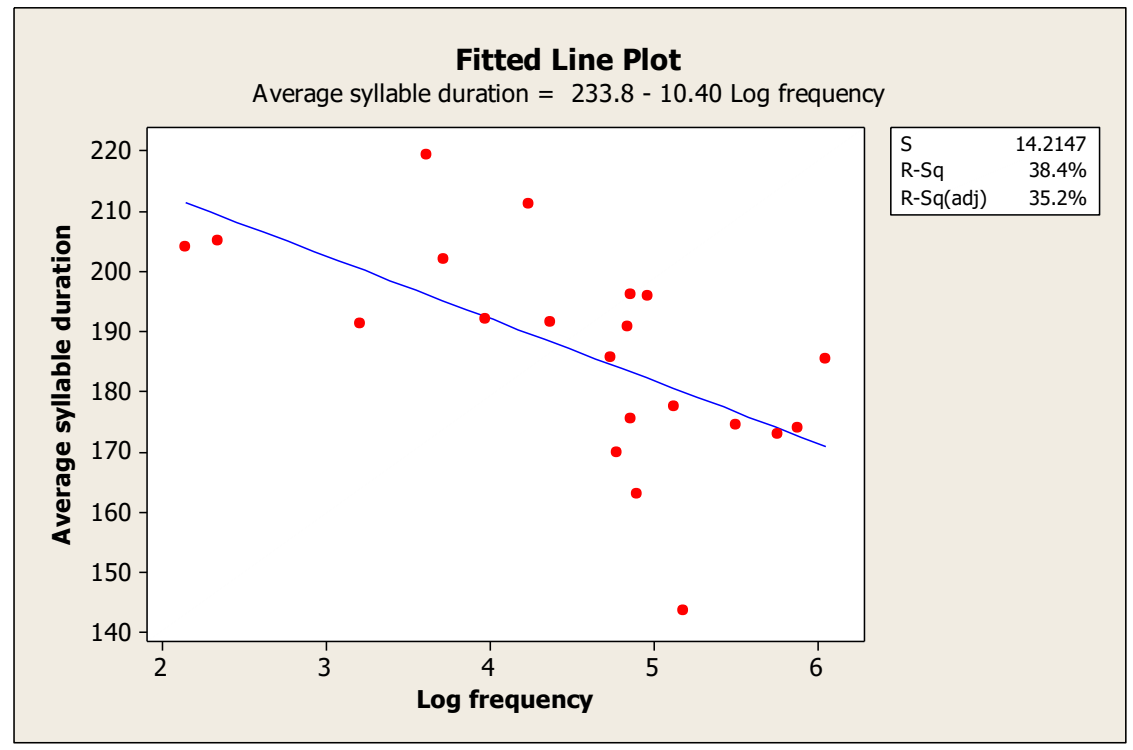

Figure 6: Frequency and duration

A second prediction comes from our analysis of Singlish initialisms as left-headed, with secondary stress decreasing from left to right. As such, we would expect the first syllable to have greater intensity and duration than the second, the second greater than the third, and so on. These stress distinctions are largely confirmed by a preliminary phonetic analysis of adjacent syllable pairs in one speaker's initialisms. Intensity is greater on the first element for a significant proportion of pairs $(\mathrm{p}<0.05)$; this also holds for duration $(\mathrm{p}<0.05)$ except that the last syllable evidently undergoes final lengthening (visible in Figure 1), although this effect has previously been reported only for utterances (Low 1998). I conclude that acoustic measures confirm the relative prominence relations that have already been inferred from tonal variation.

11. Conclusion. This study provides an analysis of tonal variation in Singlish initialisms in terms of progressive pword merger. I have argued that frequency drives pword merger via destressing, confirming this with a statistical analysis based on Google Singapore hits and tonal transcriptions from my recordings. The results also support Ng's analysis of Singlish tone as stress-dependent intonation rather than lexical tone: only by treating variation as the result of destressing are we able to correctly derive the range of observed tonal patterns.

Analyses of duration, a phonetic correlates of stress, were also consistent with this analysis, confirming that Singlish has stress rather than abstract underlying accent. Duration analyses also supported our analysis of Singlish initialisms as left-headed with respective stress.

Although an analysis based on lexical access route was rejected as inadequate, this study provides support for the mixed-route access model, because it is sensitive to properties of the whole-word unit (frequency) while also respecting stems (pword alignment).

\section{References}

Aylett, Matthew \& Alice Turk. 2004. The smooth signal redundancy hypothesis: A functional explanation for relationships between redundancy, prosodic prominence, and duration in spontaneous speech. Language and Speech 47(1). 31-56.

Baayen, R. Harald \& Robert Schreuder. 1999. War and peace: Morphemes and full forms in a noninteractive activation parallel dual-route model. Brain and Language 68. 27-32. 
Baayen, R. Harald. 1992. Quantitative aspects of morphological productivity. In Gert Booij \& Jap van Marle (eds.), Yearbook of Morphology 1991. 109-150. Dordrecht: Kluwer Academic Publishers.

Bao, Zhiming. 1998. The sounds of Singapore English. In J. A. Foley et al. (eds.). Englishes in new cultural contexts: Reflections from Singapore. 152-174. Singapore: Oxford University Press.

Bao, Zhiming. 2006. Clash avoidance and metrical opacity in Singapore English. Sprachtypologie und Universalienforschung: STUF 59(2). 133-147.

Beckman, Mary E., Julia Hirschberg \& Stefanie Shattuck-Hufnagel. 2005. The original ToBI system and the evolution of the ToBI framework. In Sun-Ah Jun (ed.), Prosodic typology: The phonology of intonation and phrasing. Oxford: Oxford University Press. https://doi.org/10.1093/acprof:oso/9780199249633.001.0001.

Bell, Alan, Jason M. Brenier, Michelle Gregory, Cynthia Girand, \& Dan Jurafsky. 2009. Predictability effects on durations of content and function words in conversational English. Journal of Memory and Language 60. 92-111. https://doi.org/10.1016/j.jm1.2008.06.003.

Brown, Adam. 1988. The staccato effect in the pronunciation of English in Malaysia and Singapore. In Joseph Foley (ed.), New Englishes: The case of Singapore. 115-128. Singapore: Singapore University Press.

Bybee, Joan. 2006. From usage to grammar: The mind's response to repetition. Language 82(4). 711-733. https://doi.org/10.1353/lan.2006.0186.

Deterding, David. 2001. The measurement of rhythm: A comparison of Singapore and British English. Journal of Phonetics 29(2). 217-230. https://doi.org/10.1006/jpho.2001.0138.

Deterding, David. 2005. Emergent patterns in the vowels of Singapore English. English World Wide 26(2). 179-97.

Deterding, David. 2007. Singapore English. Edinburgh: Edinburgh University Press.

Ferreira, Fernanda. 1993. Creation of prosody during sentence production. Psychological Review 100(2). 233-253.

Flack, Kathryn. 2007. The sources of phonological markedness. Ph.D. dissertation, University of Massachusetts, Amherst.

Fosler-Lussier, Eric \& Nelson Morgan. 1999. Effects of speaking rate and word frequency on pronunciations in conversational speech. Speech Communication 29(2-4). 137-158.

Gahl, Susanne. 2008. Time and thyme are not homophones: The effect of lemma frequency on word durations in spontaneous speech. Language 84(3). 474-496. 10.1353/lan.2018.0032.

Gouskova, Maria \& Kevin Roon. to appear. Interface constraints and frequency in Russian compound stress. In Formal Approaches to Slavic Linguistics 17.

Gupta, Anthea Fraser. 1992. The pragmatic particles of Singapore Colloquial English. Journal of Pragmatics 18. 31-57.

Gupta, Anthea Fraser. 1998. The situation of English in Singapore. In J. A. Foley et al., Englishes in New Cultural Contexts: Reflections from Singapore. 41-72. Singapore: Oxford University Press.

Guy, Gregory R., Jennifer Hay \& Abby Walker. 2008. Phonological, lexical, quency factors in coronal stop deletion in Early New Zealand English. Poster at Laboratory Phonology 11, Wellington, New Zealand, 30 June-2 July.

Hall, Tracy Alan. 1999. The phonological word: A review. In Tracy Alan Hall \& Ursula Kleinhenz (eds.), Studies on the phonological word. 1-22. Amsterdam; Philadelphia: John Benjamins. 
Harley, Heidi. 2004. Why is it the CIA but not *the NASA? Acronyms, initialisms and definite descriptions. American Speech 74(4). 368-399.

Hay, Jennifer. 2003. Causes and consequences of word structure. Outstanding dissertations in linguistics, New York; London: Routledge.

Hayes, Bruce. 1995. Metrical stress theory: Principles and case studies. Chicago: University of Chicago Press.

Inkelas, Sharon. 1989. Prosodic constituency in the lexicon. Ph.D. dissertation, Stanford University.

Killingley, Siew-Yue. 1972. Clause and sentence types in Malayan English. Orbis 21(2). 537-548.

Liberman, Mark \& Alan Prince. 1977. On stress and linguistic rhythm. Linguistic Inquiry 8(2). 249-336.

Low, Ee Ling \& Esther Grabe. 1999. A contrastive study of prosody and lexical stress placement in Singapore English and British English. Language and Speech 42(1). 39-56.

Low, Ee Ling, Esther Grabe \& Francis Nolan. 2000. Quantitative characterizations of speech rhythm: Syllable-timing in Singapore English. Language and Speech 43(4). 377-401. Low,

Ee Ling. 1998. Prosodic prominence in Singapore English. Ph.D. dissertation, Cambridge.

McCarthy, John J. \& Prince, Alan. 1993. Generalized alignment. Yearbook of Morphology 12.

McCarthy, John J. \& Alan Prince. 1993. Prosodic morphology: Constraint interaction and satisfaction.

McCarthy, John J. 2003. OT constraints are categorical. Phonology 20. 75-138.

McCormick, Samantha F., Marc Brysbaert \& Kathleen Rastle. 2009. Is morphological decomposition limited to low-frequency words? The Quarterly Journal of Experimental Psychology 62(9). 1706-1715.

Myers, James \& Yingshing Li. 2009. Frequency effects in Southern Min syllable contraction. Journal of Phonetics 37(2). 212-230.

Nespor, Marina \& Irene Vogel. 1986. Prosodic phonology. Dordrecht: Foris.

Ng, E-Ching. 2008a. Malay meets Chinese meets English: Where does Colloquial Singaporean English word-level tone come from? Presented at Interdisciplinary approaches to transfer, crosslinguistic influence and contact-induced change workshop, 11 July, UWE Bristol.

$\mathrm{Ng}$, E-Ching. 2008b. Affixation, compounding and the prosodic word in Singaporean English. Presented at Workshop on Prosodic Alignment at the Word Level, 20-21 Nov, Institut für Deutsche Sprache, Mannheim.

Ng, E-Ching. 2009. Non-Plateaus, Non-Tonal Heads: Tone assignment in Colloquial Singaporean English. Chicago Linguistic Society (CLS) 45(1). 487-501.

Ng, E-Ching. 2010. Reduction, frequency and morphology in Singaporean English prosody. Rutgers Optimality Archive \#1102. http://roa.rutgers.edu/article/view/1132.

$\mathrm{Ng}$, E-Ching. 2011. Reconciling stress and tone in Singaporean English. In Lawrence J. Zhang, Rani Rubdy \& Lubna Alsagoff (eds.), Asian Englishes: Changing perspectives in a globalised world. 76-92. Singapore: Pearson Longman.

Ng, E-Ching. 2012. Chinese meets Malay meets English: Origins of Singaporean English wordfinal high tone. Special issue of the International Journal of Bilingualism 16(1). 83-100. https://doi.org/10.1177/1367006911403216.

Pater, Joe. 2001. Austronesian nasal substitution revisited. In Linda Lombardi (ed.), Segmental phonology in Optimality Theory: Constraints and representations. 159-182. Cambridge University Press.

Peperkamp, Sharon. 1997. Prosodic Words. HIL dissertations 34, The Hague: Holland Academic Graphics. 
Pierrehumbert, Janet B. \& David Talkin. 1992. Lenition of /h/ and glottal stop. In Gerard J. Docherty \& D. Robert Ladd (eds.), Gesture, segment, prosody, Papers in Laboratory Phonology 2. 90-127. Cambridge: Cambridge University Press.

Pluymaekers, Mark, Mirjam Ernestus \& R. Harald Baayen. 2005. Lexical frequency and acoustic reduction in spoken Dutch. Journal of the Acoustical Society of America 118(4). 2561-2569.

Raffelsiefen, Renate. 1999. Diagnostics for prosodic words revisited: The case of historically prefixed words in English. In T. Alan Hall \& Ursula Kleinhenz (eds.), 133-202. Studies on the Phonological Word. Amsterdam; Philadelphia: John Benjamins.

Redi, Laura \& Stefanie Shattuck-Hufnagel. 2001. Variation in the realization of glottalization in normal speakers. Journal of Phonetics 29. 407-429. https://doi.org/10.1006/jpho.2001.0145.

Rubach, Jerzy. 2000. Glide and glottal stop insertion in Slavic languages: A DOT analysis. Linguistic Inquiry 31(2). 271-317. https://doi.org/10.1162/002438900554361.

Selkirk, Elisabeth O. 1984. Phonology and syntax: The relation between sound and structure. Cambridge, MA: MIT Press.

Selkirk, Elisabeth O. 1995. The prosodic structure of function words. In J. Beckman, L. Walsh Dickey, \& S. Urbanczyk (eds.), University of Massachusetts Occasional Papers in Linguistics, Papers in Optimality Theory 18, 439-469. Amherst, MA: GLSA.

Singapore Department of Statistics. 2011. Singapore Census of Population 2010, Statistical Release 1: Demographic characteristics, education, language and religion. Singapore: Ministry of Trade and Industry.

Siraj, Pasha. 2008. Stress-dependent word tone in Singaporean English. Poster at TIE 3, 15 Sept, Lisbon, Portugal.

Smith, Jennifer L. 2002. Phonological augmentation in prominent positions. Ph.D. dissertation, University of Massachusetts, Amherst.

Son, R. J. J. H. van \& Louis C. W. Pols. 2003. How efficient is speech? In Proceedings of the Institute of Phonetic Sciences 25, 171-184.

Tan, Ying Ying. 2002. Acoustic and perceptual properties of stress in the ethnic subvarieties of Singapore English. Ph.D. dissertation, National University of Singapore.

Tay, Mary W. J. 1982. The phonology of educated Singapore English. English World-Wide 3(2). $135-145$.

Tongue, Ray K. 1979. The English of Singapore and Malaysia, 2nd edn. Singapore: Eastern Universities Press.

Umeda, Noriko. 1978. Occurrence of glottal stops in fluent speech. Journal of the Acoustical Society of America 64. 88-94.

Walker, James A. Form, function, and frequency in Phonology: (t/d)-Deletion in Toronto. New Ways of Analyzing Variation 37, Rice University, Houston, TX, 6-9 Nov.

Wee, Lian-Hee. 2008. More or less English: Two phonological patterns in the Englishes of Singapore and Hong Kong. World Englishes 27(3/4). 480-501.

Wee, Lian-Hee. 2016. Tone assignment in Hong Kong English. Language 92(2). e67-e87. Wells, J. C. 2000. Longman pronunciation dictionary. Harlow, UK: Pearson Education Ltd. Zuraw, Kie. 2007. Frequency influences on rule application within and across words. In Chicago Linguistic Society 43. 